\title{
UniFHy v0.1: A community framework for the terrestrial water cycle in Python
}

Thibault Hallouin ${ }^{1,2}$, Richard J. Ellis ${ }^{3}$, Douglas B. Clark ${ }^{3}$, Simon J. Dadson ${ }^{3,4}$, Andrew G. Hughes ${ }^{5}$, Bryan N. Lawrence ${ }^{1,2,6}$, Grenville M. S. Lister ${ }^{1,2}$, and Jan Polcher ${ }^{7}$

${ }^{1}$ National Centre for Atmospheric Science, UK

${ }^{2}$ Department of Meteorology, University of Reading, UK

${ }^{3}$ UK Centre for Ecology \& Hydrology, UK

${ }^{4}$ School of Geography and the Environment, University of Oxford, UK

${ }^{5}$ British Geological Survey, UK

${ }^{6}$ Department of Computer Science, University of Reading, UK

${ }^{7}$ Laboratoire de Météorologie Dynamique, IPSL, CNRS, France

Correspondence: Thibault Hallouin (th.thibault.hallouin@ gmail.com)

\begin{abstract}
Land surface, hydrological, and groundwater modelling communities all have expertise in simulating the hydrological processes at play in the land system, but these communities have largely remained distinct with limited collaboration between disciplines. In order to address key societal questions regarding the future availability of water resources and the intensity of extreme events such as floods and droughts in a changing climate, these communities must build on the strengths of one another. The development of a common modelling infrastructure, a framework, can contribute to stimulating cross-fertilisation between them. By allowing (parts of) their existing models to be coupled together, improved land system models can be built to better understand and simulate the terrestrial hydrological cycle. This paper presents a Python implementation of such a framework named the Unified Framework for Hydrology (unifhy). The framework aims to provide the technical infrastructure required to couple models, taking into account the specific needs of a land system model. Its conceptual design and technical capabilities are outlined first, before its usage and useful characteristics are demonstrated through case studies. The limitations of the current framework and necessary future developments are finally presented as a road map for later versions and/or other implementations of the framework.
\end{abstract}

\section{Introduction}

The Earth's atmosphere and land surface are deeply interconnected systems. Given this, hydrological knowledge is as critical to atmospheric scientists as meteorological knowledge is to hydrologists. Land surface models have historically been developed as a lower boundary condition to atmospheric models which, to this day, partially explains the shortcomings in the representation of hydrological processes in land surface models. Indeed, the resolution of the land system coupled with the atmosphere has typically been too coarse to adequately represent the spatial structures of the dominant hydrological processes, while the focus on vertical exchanges between the land and the atmosphere has limited the development of the critical lateral redistribution of water on and below the ground. To overcome these limitations, a modular representation of the terrestrial water cycle using 
https://doi.org/10.5194/gmd-2021-419

Preprint. Discussion started: 16 December 2021

(c) Author(s) 2021. CC BY 4.0 License.

(c) (i)

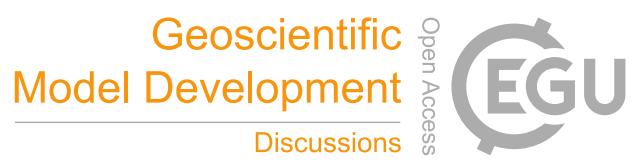

interconnected modelling components would provide the flexibility required in the spatial discretisation of the land system while preserving the existing coupling approaches with atmospheric models. In addition, such modularity would contribute to developing and comparing alternative representations of the real-world land system and assessing their impacts on hydrological and atmospheric predictions alike.

The land surface modelling community has developed highly configurable models such as the Joint UK Land Environment Simulator (JULES) (Best et al., 2011; Clark et al., 2011), the Organising Carbon and Hydrology In Dynamic Ecosystems (ORCHIDEE) model (Krinner et al., 2005), and the Community Land Model (Lawrence et al., 2019). However, these models do not allow different parts of the land system to be simulated at different explicit resolutions (except for the runoff routing), nor do they make it possible to substitute part of one model with another part from another model. The community has developed coupling frameworks for the land system, e.g. Landlab (Hobley et al., 2017) can be used to develop modelling components complying with the Basic Modelling Interface (BMI) (Peckham et al., 2013; Hutton et al., 2020) that can be coupled using the Python Modelling Toolkit (Hutton et al., 2021), although as yet none of the existing land surface models above are built using such technologies.

The hydrological modelling community has also been developing frameworks to compare different physical processes and/or conceptualisations of the hydrological behaviour of a catchment. For example, FUSE (Clark et al., 2008), SUPERFLEX (Fenicia et al., 2011), and CMF (Kraft et al., 2011) provide bucket-style building blocks to develop integrated catchment models, while SUMMA (Clark et al., 2015) and Raven (Craig et al., 2020) allow the construction of physically-explicit hydrological models using process equations as the building blocks. However, refactoring existing land surface models using these frameworks is not trivial, and an intermediate level of modularity is required. The Open Modelling Interface (OpenMI) has been developed to provide an international standard to link hydrological and hydraulic models as components. It has been implemented as a flexible approach for allowing models as components to be linked at runtime (Harpham et al., 2019).

Such intermediate modularity is already a reality within the Earth system modelling community, where atmosphere, ocean, and land components together simulate the dynamics of the Earth system. The technologies used to combine such modelling components range from integrated coupling frameworks such as ESMF (Collins et al., 2005) or CPL7 (Craig et al., 2012), where existing modelling components require code refactoring to comply with a set of organising and interfacing requirements, to couplers such as OASIS-MCT (Valcke, 2013; Craig et al., 2017), or YAC (Hanke et al., 2016), where existing modelling components require minimal additions to expose their variables to the coupler. While these two families of frameworks vary in the level of intrusiveness into the existing code, they both offer access to essential functionalities such as I/O, parallelism, flexible spatial discretisation, remapping, and so on. This experience and these technologies ought to be exploited to build modular frameworks to form a new generation of land system models.

In this manuscript, a new framework for modelling the hydrological cycle in the land system is described, inspired by the modularity of existing Earth system modelling frameworks. It follows an integrated coupling philosophy featuring three framework components interconnected through standardised interfaces allowing new science components to be embedded into the framework with minimal refactorisation of their interfaces. Section 2 expands on its design principles and implementation details, Section 3 showcases usage of the framework, Section 4 details how to contribute to the framework with new science 
https://doi.org/10.5194/gmd-2021-419

Preprint. Discussion started: 16 December 2021

(c) Author(s) 2021. CC BY 4.0 License.

(c) (i)

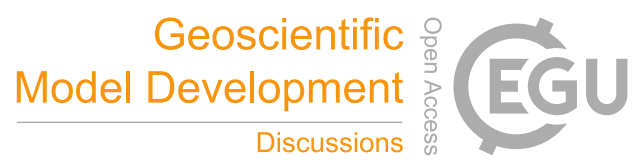

components, Section 5 demonstrates the capabilities of the framework on case studies, and finally Section 6 explores avenues for future developments.

\section{Description of the framework}

\subsection{Modular water cycle blueprint}

Given the dominant spatial structures and temporal scales of the processes involved in the terrestrial water cycle, and the interconnected nature of the land system with the atmosphere and the ocean, a modular blueprint featuring three framework components is chosen (see Figure 1): a surface layer component encapsulating the dynamics of moisture and energy exchanges between the atmosphere and the Earth's surface, which are amongst the fastest processes in the terrestrial water cycle and predominantly uni-directional (i.e. vertical); a subsurface component to address the movement of water through the soil down to the bedrock, which in comparison tends to be slower and truly tri-directional (i.e. lateral redistribution according to topographic and hydraulic head gradients, and vertical percolation/capillary rise/vegetation uptake); and an open water component for the movement of free water in contact with the atmosphere which is of intermediate speed and predominantly bi-directional along the surface of the Earth towards the seas and oceans. Despite this modularity, each component must be conservative with respect to the quantities in the continuity equations so that these are also conserved across the entire land system.

For existing modelling components to be coupled, outputs from one need to be mapped onto inputs for another: this requires a common bank of defined variables to guarantee that the output of one is semantically equivalent to the input of the other. Moreover, to maximise the chances of finding compatible models, this calls for a common interface between components that skilfully yet pragmatically subdivides the terrestrial water cycle continuum. Indeed, a compromise must be found between allowing flexibility in model construction and maximising the potential for existing models to be incorporated in the framework. This is why a standard interface between the components of the framework is formulated. This interface is a set of prescribed transfers of information between each pair of components in the blueprint. For instance, the open water component is receiving (i.e. inward transfers) 'direct throughfall flux', 'water evaporation flux from open water', 'surface runoff flux delivered to rivers', and 'net subsurface flux to rivers' while it is sending (i.e. outward transfers) 'open water area fraction' and 'open water surface height' (see Figure 1 and Table 1). These interfaces define the relationship between the framework components.

80 They were designed considering the existing structure of land surface models, namely JULES (Best et al., 2011; Clark et al., 2011) and ORCHIDEE (Krinner et al., 2005). The information transferred through the interface includes the fluxes necessary to fulfil the continuity equations across the entire land system, as well as the diagnostic quantities characterising the state of components which necessarily condition fluxes in other components.

\subsection{Integrated coupling approach}

85 A first implementation of this blueprint is developed in Python (Hallouin and Ellis, 2021) as an integrated coupling framework following an object oriented approach (see Figure 2 for a visual overview of the software architecture using the Unified 


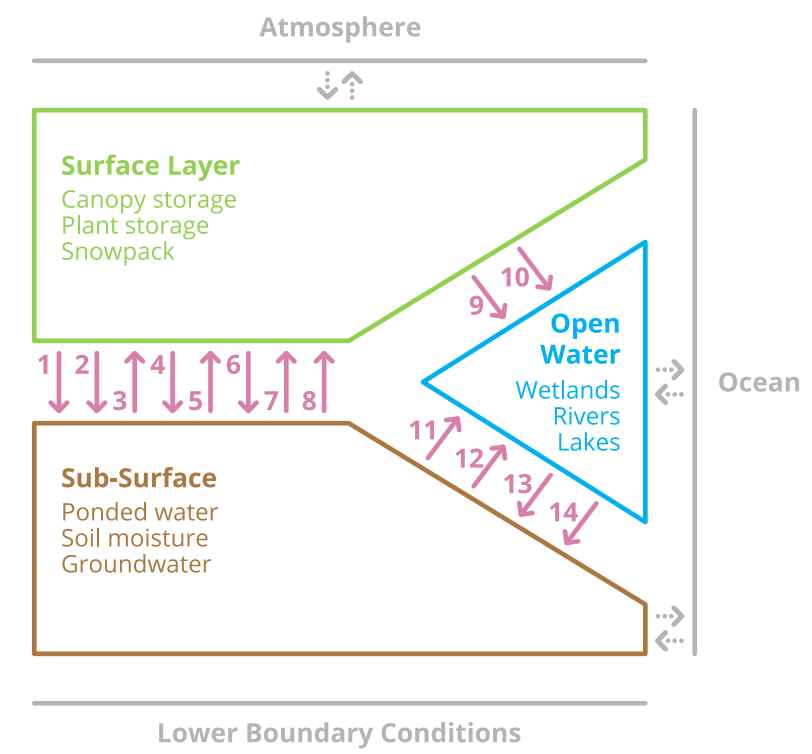

Figure 1. Schematic blueprint of the terrestrial water cycle featuring the three components 'Surface Layer', 'Sub-Surface', and 'Open Water', their transfers of information as numbered arrows (see Table 1), and their relationships with external models (atmosphere and ocean).

Modelling Language (UML)). Object oriented programming is ideally suited to efficiently implement such modular software, and the inheritance of the core functionalities of a framework component allows for code reuse in the constitution of the various subdivisions of the water cycle and the community-based component contributions. In this framework, three Component objects are coupled together by a Model object and executed concurrently, so that the order in which the components are called does not impact on the outcome of the simulation. The Model is responsible for the exchange of information between components, including their potential temporal accumulation and aggregation and/or their potential spatial remapping (using an Exchanger object), and is responsible for the time iteration of all components (using a Clock object).

The Component object provides infrastructure to support the science component; e.g. reading input (using Dataset objects), writing output (using Record and RecordStream objects), and state memory allocation (using State objects). The Component class itself is subclassed into the actual framework components represented by the SurfaceLayerComponent, SubSurfaceComponent, and openWaterComponent classes, which are used to enforce inward and outward transfers corresponding to the framework interfaces. Each accommodates the description of the physical processes of a given part of the terrestrial water cycle (i.e. the science component) following an initialise-run-finalise paradigm. DataComponent and NullComponent classes are also provided as a convenience to allow any of the three framework components to be either replaced with appropriate data or removed. In both cases the replacement generates outward data transfers, in the former case, from data, in the latter case, zeros. Attempted inward data transfers are quietly ignored. 
Table 1. Prescribed interface variables defining what must be transferred between the framework components.

\begin{tabular}{lll}
\hline$\#$ & Name & Unit \\
\hline 1 & canopy_liquid_throughfall_and_snow_melt_flux & $\mathrm{kg} \mathrm{m}^{-2} \mathrm{~s}^{-1}$ \\
2 & transpiration_flux_from_root_uptake & $\mathrm{kg} \mathrm{m}^{-2} \mathrm{~s}^{-1}$ \\
3 & soil_water_stress_for_transpiration & 1 \\
4 & direct_water_evaporation_flux_from_soil & $\mathrm{kg} \mathrm{m}^{-2} \mathrm{~s}^{-1}$ \\
5 & soil_water_stress_for_direct_soil_evaporation & 1 \\
6 & water_evaporation_flux_from_standing_water & $\mathrm{kg} \mathrm{m}^{-2} \mathrm{~s}^{-1}$ \\
7 & standing_water_area_fraction* & 1 \\
8 & total_water_area_fraction* & 1 \\
9 & water_evaporation_flux_from_open_water & $\mathrm{kg} \mathrm{m}^{-2} \mathrm{~s}^{-1}$ \\
10 & direct_throughfall_flux & $\mathrm{kg} \mathrm{m}^{-2} \mathrm{~s}^{-1}$ \\
11 & surface_runoff_flux_delivered_to_rivers & $\mathrm{kg} \mathrm{m}^{-2} \mathrm{~s}^{-1}$ \\
12 & net_groundwater_flux_to_rivers & $\mathrm{kg} \mathrm{m}^{-2} \mathrm{~s}^{-1}$ \\
13 & open_water_area_fraction* & 1 \\
14 & open_water_surface_height & $\mathrm{m}$ \\
\hline
\end{tabular}

* Standing and open water both refer to the water on the land surface in direct contact with the atmosphere, but the former corresponds to the ephemeral water on the land surface, while the latter corresponds to the water in rivers and lakes. Total water refers to the combination of standing and open water, taking into account any overlap between the two.

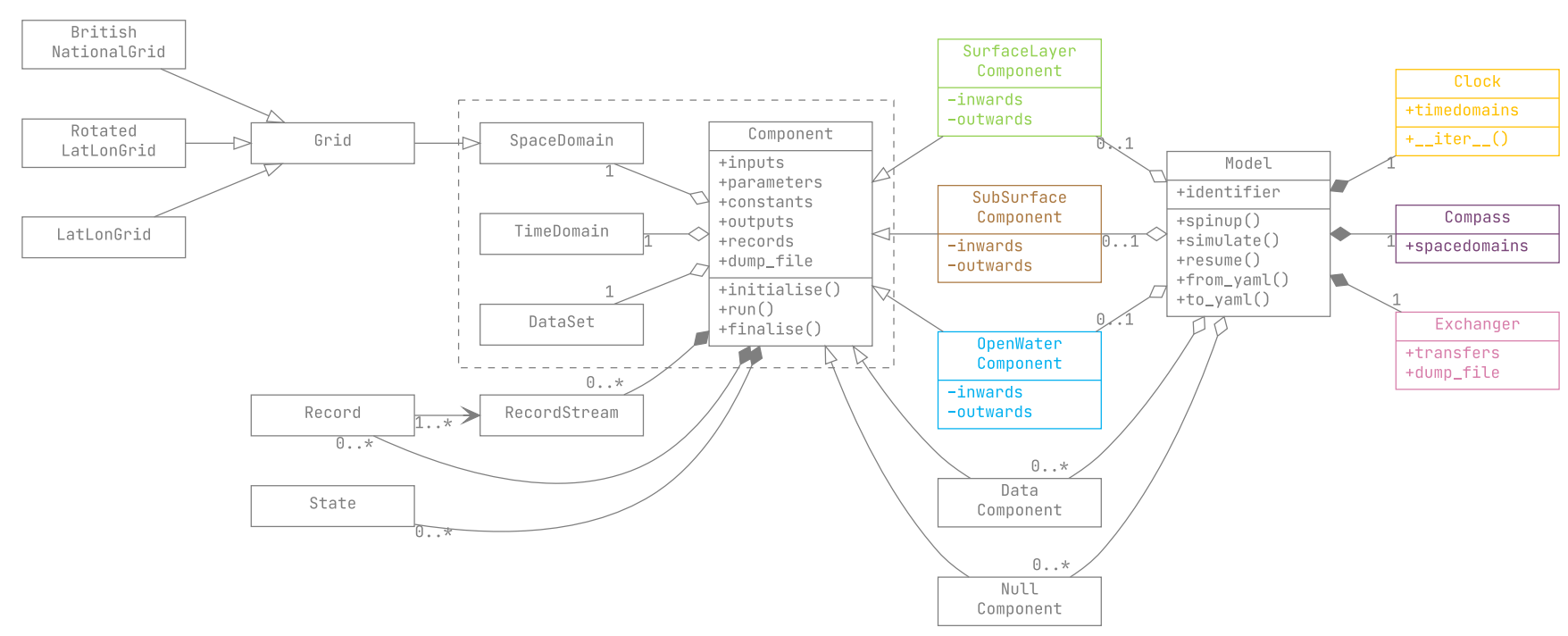

Figure 2. UML class diagram of the unifhy Python package. 


\subsection{Flexible discretisation}

The framework modularity makes it possible to resolve the processes in each science component at their own temporal and spatial resolutions. Each Component is discretised individually with its own instances of the TimeDoma in and SpaceDoma in classes defining their temporal and spatial discretisations, respectively.

In the framework, the TimeDomain class limits instances to temporal discretisations that are regularly-spaced. While each component could theoretically run on any temporal resolution independent of the resolution of the other components, it is essential to make sure that restarting times exist across the simulation period in case of unexpected interruption of the execution. In order to achieve this, the $\mathrm{Clock}$ object makes sure that the temporal resolutions are constrained such that, across the three components, the component temporal resolutions are required to be integer multiples of each other, and the component temporal extents to span the same simulation period.

In the framework, the SpaceDomain class is subclassed into a Grid, intended to encompass all structured gridded spatial discretisations. The distinction between SpaceDoma in and Grid is done in anticipation of additional subclasses to be created in the future (see subsection 6.2). The Grid class itself currently features three subclasses corresponding to two discretisations on spherical coordinate systems (latitude-longitude and rotated-pole latitude-longitude) as well as one discretisation on a Cartesian (projected) coordinate system (the British national grid), but additional subclasses can easily be developed. Internal spatial remapping between differing component discretisations relies on the remapping functionality provided by ESMF (Collins et al., 2005). If components are to be resolved on different spatial discretisations, not only the components must conserve the quantities in the continuity equations, but the remapping operation must also be conservative. Discontinuities being intrinsic to the land system, e.g. in land cover or soil properties, it appears unrealistic to directly apply traditional interpolation methods for the remapping since they assume continuity, whereas supermeshing techniques (Farrell et al., 2009), where a supermesh is the union of the components meshes, offer solutions to remain conservative in the remapping without the need for a continuity assumption. Since the current implementation of the framework does not yet feature an explicit supermeshing technique across the three components, the Compass object makes sure that components are discretised using space domains of the same class (i.e. in the same coordinate system), that they span the same region, and that their spatial resolutions are encapsulated in one another, which effectively guarantees that for each pair of coupled components, one is the supermesh for both of them.

\subsection{Open science library}

Alongside the framework infrastructure itself, an initial library of open source science components complying with the standard framework interface is available. This allows users to explore alternative combination of components as alternative solutions to simulate the terrestrial water cycle.

Additional components can be exploited by the framework so long as they comply, or can be made to comply, with the framework interface via a particular Python class template (see Script 7). 

components with the rest of the community. These contributions can be implemented purely in Python, but can also rely on Fortran, $\mathrm{C}$, or $\mathrm{C}++$ programs called by interface middleware. Contributors need not handle basic functionalities such as memory allocation nor input/output operations, as these are handled by the framework. Ideally, the use of the framework will simplify model development allowing framework contributors to focus on scientific development (see section 4).

\subsection{Meaningful data}

The interface specification is effectively a data specification. To guarantee the unambiguous specification of that interface, as well as to bring to the framework and to users alike a full awareness of the physical meaning and spatio-temporal context of input and output data, the NetCDF Climate and Forecast (CF) Metadata Conventions (Eaton et al., 2020) are exploited in the framework. These conventions provide a robust guide for describing, processing, and sharing geophysical data files. They are used in a variety of applications, including for global model inter-comparison efforts such as CMIPs (e.g. Eyring et al., 2016).

The Dataset class responsible for providing each Component with input data relies on reading CF-NetCDF files. This enables the framework to check the compatibility between the data and the configured component, both physically and spatiotemporally. In addition, all record files and dump files are generated as CF-NetCDF files. Such CF-NetCDF files are processed with the package cf-python (Hassell et al., 2017; Hassell and Bartholomew, 2020).

\section{Usage of the framework}

\subsection{Configuration}

In this section, the framework configuration workflow is presented. The user can configure the framework either using the Application Programming Interface (API) directly, or using an intermediate YAML (Yet Another Markup Language) configuration file.

\subsubsection{Application Programming Interface}

The first step in this workflow is to define the temporal and spatial discretisations. The user has to instantiate TimeDoma in and SpaceDoma in objects. The framework comes with a variety of constructor methods for these two objects, including using existing data structures, e.g. from_field, or using the limits and spacing of the discretisation, e.g. from_start_end_step for TimeDomain and from_extent_and_resolution for SpaceDomain. Examples using the latter are presented in Script 1.

The second step consists in selecting the NetCDF files containing the input data. To do so, the user has to instantiate a Dataset object (Script 2). These files must comply with the CF-conventions (subsection 2.5).

The third step, which completes the configuration of a Component, is to provide these three objects to the selected component alongside values with units for the component parameters and constants. Additionally, the user can select the variables to 


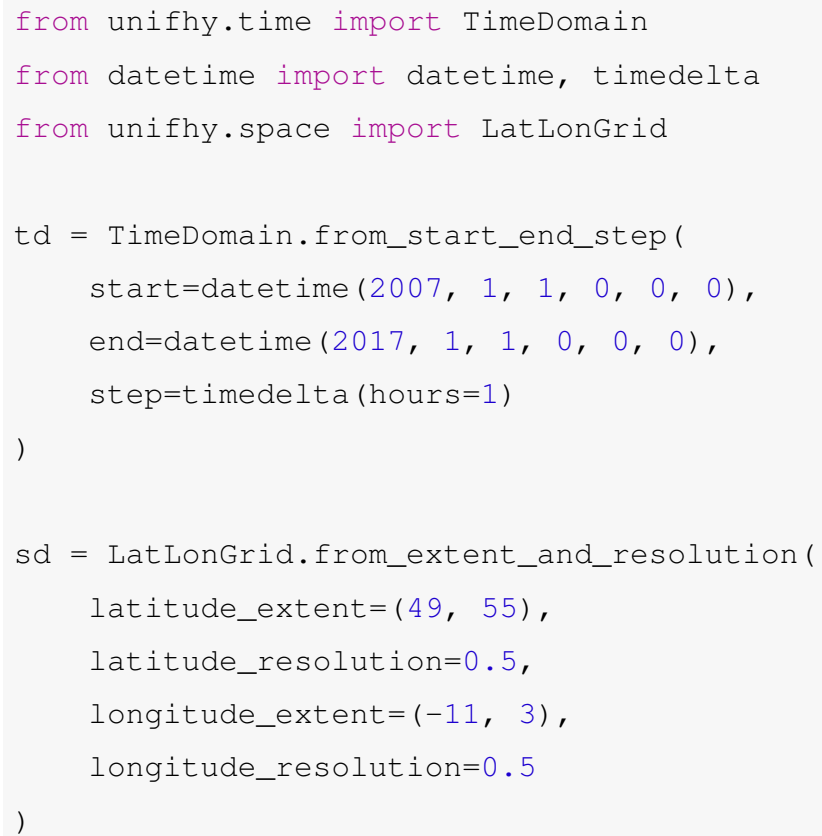

Script 1. Example of temporal discretisation (to generate hourly timestepping), and spatial discretisation (to generate a regular $0.5^{\circ}$ latitudelongitude grid) using the framework's API.

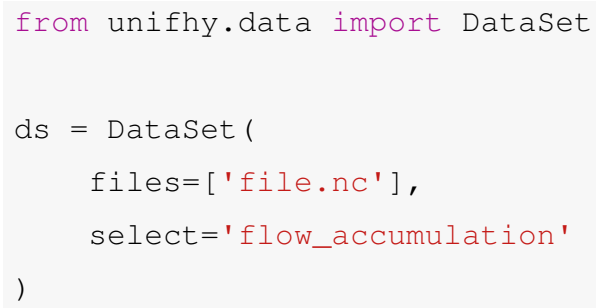

Script 2. Example of data specification using the framework's API: selecting a variable in a CF-NetCDF file. 
record for this component, whether component outward transfers and/or component outputs and/or component states with customisable temporal resolution (multiple of its TimeDomain resolution) and summary statistics (mean, minimum, maximum, instantaneous). In Script 3, the open water science component RFM, based on the RFM model (Bell et al., 2007; Dadson et al., 2011), is used and configured. Instantiating a Component will be successful only if all the inputs, parameters, and constants required by the science component are provided and compatible in names, units, time and space dimensions with the component and its time and space domains.

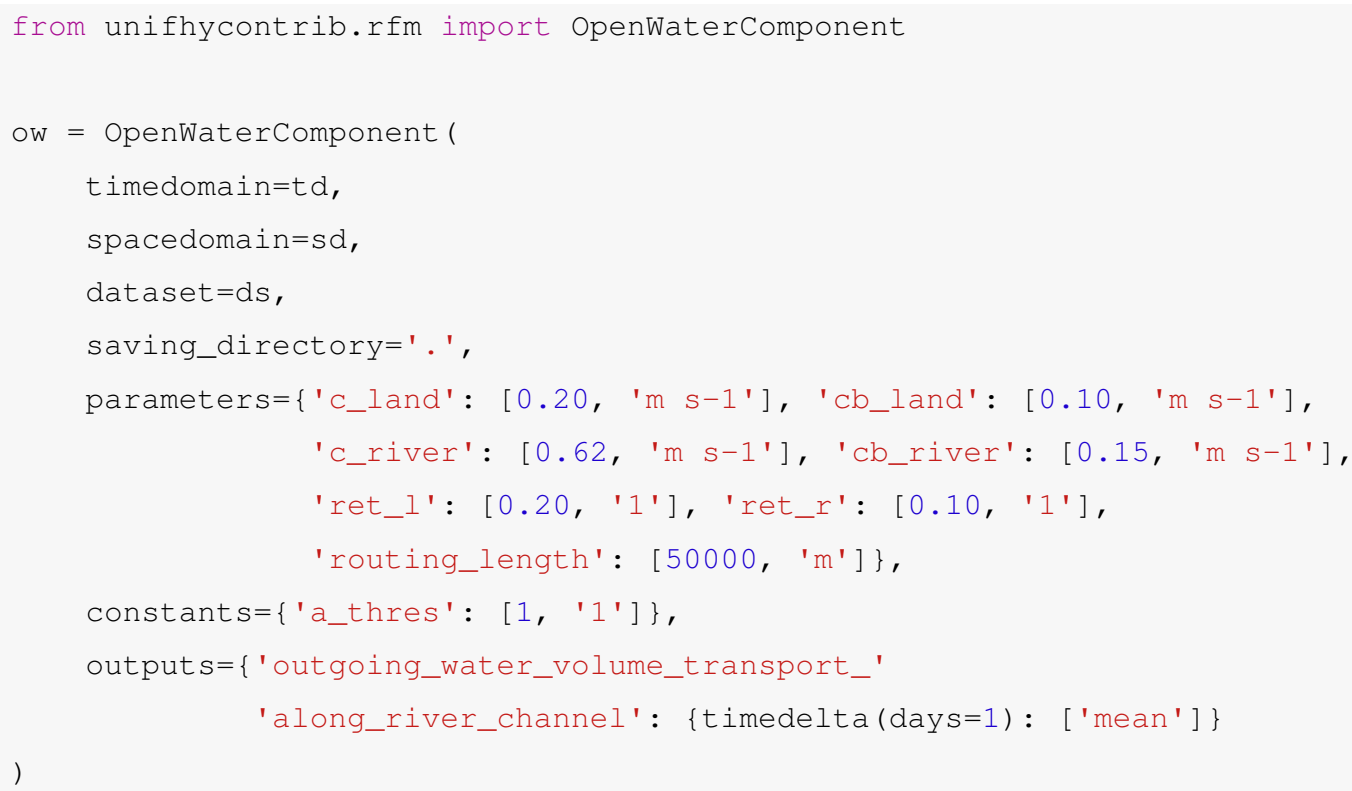

Script 3. Example of component configuration using the framework's API: an open water component based on the RFM model.

The fourth and last step in the configuration workflow is to gather three components, one of each of the three types SurfaceLayerComponent, SubSurfaceComponent, and openWaterComponent to form a model. In Script 4, the variables 'sl', 'ss', and 'ow' are instances of each, respectively, configured similarly to the example in Script 3.

Note, the three components forming the model need to comply with the temporal and spatial discretisation constraints formulated in subsection 2.3 for the instantiation of a Model to be successful.

\subsubsection{Configuration file}

An alternative to the API is the use of a configuration file written using the human-readable serialisation language YAML. This provides both a more accessible configuration approach for users less comfortable with programming and a way to easily share configurations with other users. The complete configuration workflow presented above using the API can be formulated in a 


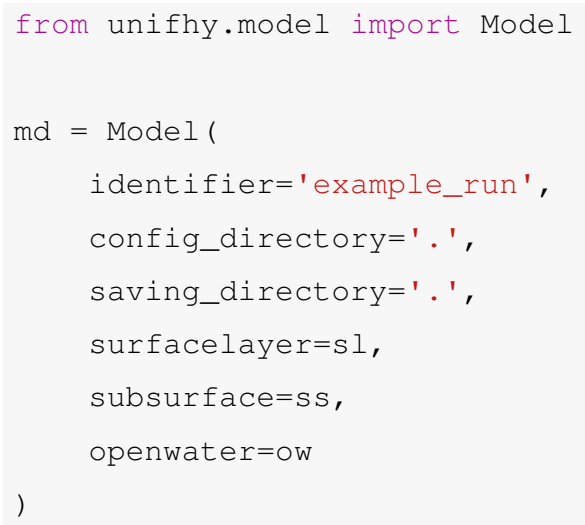

Script 4. Example of model configuration using the framework's API.

single YAML file. For reasons of brevity, only an equivalent for the third step above, i.e. configuring one component (Script 3), is presented in Configuration 1. Entire configuration files can be found in the Supplement.

Configuration files can then be loaded using the API to instantiate the Model directly (Script 5). Note, after the successful instantiation of a Model using the API (i.e. Script 4), such a YAML file is automatically created in the configuration directory.

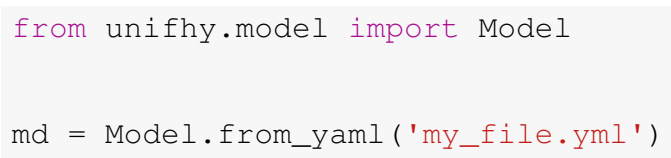

Script 5. Example using the framework's API to instantiate a Model from a YAML configuration file.

\subsection{Simulation}

A configured Model can then be used to start model spin-up cycle(s) and/or to start a simulation run over the entire simulation period specified in the time domains of the components (Script 6). The spin-up period can either be within or outside of the simulation period, so long as the datasets given to the components contain data for it.

Both spin-up and simulation runs can produce dump files, that is files containing intermediate snapshots in the simulation period with all the information required to resume the simulation in case of an unexpected interruption. The user can specify a dumping frequency to choose how often such snapshots should be saved. Once the Model is re-instantiated using its configuration file created through Script 4, the simulation can be resumed using any snapshot in these dump files. Moreover, these files can be used to provide initial conditions for the component states in replacement or in addition to the spin-up cycles. 


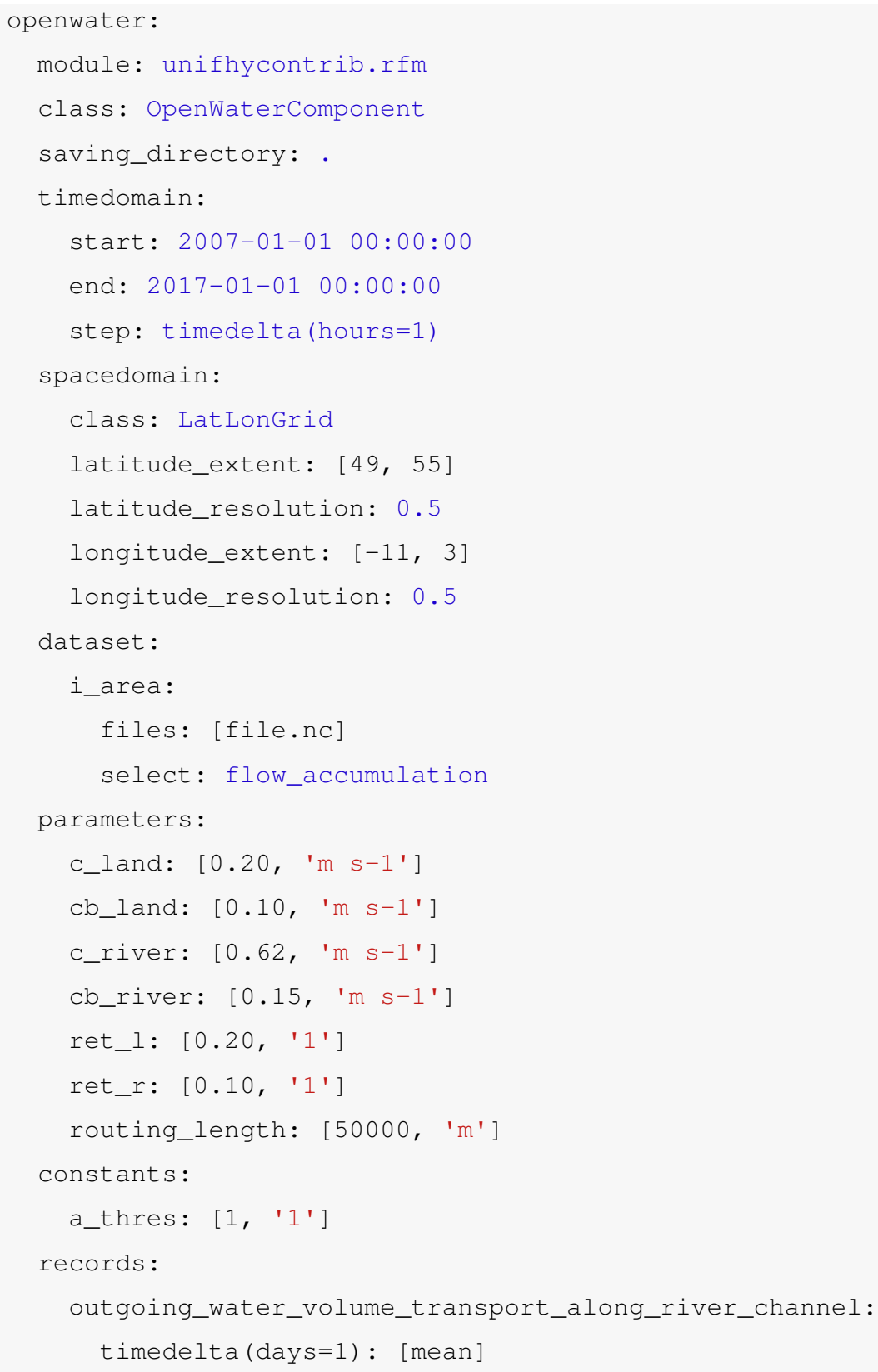

Configuration 1. Excerpt from YAML configuration file equivalent to Script 3. 


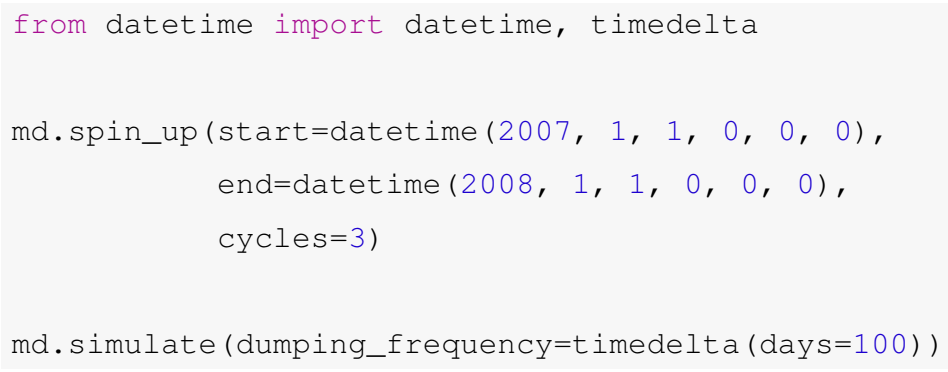

Script 6. Example using the framework's API to start simulations with a Model.

\section{Contribution to the framework}

If the science components already available in the open science library (subsection 2.4) are not sufficient or suitable for the needs of users, they have the opportunity to create their own. New science components for use in the framework can be developed as Python subclasses of the framework's internal SurfaceLayerComponent, SubSurfaceComponent, and openWaterComponent classes.

The approach to developing a science component is designed to require minimal development effort, and can be divided into five steps. The first step is to declare a Python class whose base class is one of the SurfacelayerComponent, SubSurfaceComponent, or OpenWaterComponent classes (e.g. lines 1-3 in Script 7). The second step is to provide a description for the component using the docstring of the class (e.g. line 4 in Script 7). The third step is to declare the component interface, i.e. to indicate which transfers in the standard interface are used and produced (e.g. lines 7-8 in Script 7). The fourth step is to define the component characteristics, including its inputs, parameters, constants, states, and outputs in their corresponding class attributes (e.g. lines 9-23 in Script 7). The fifth and last step is to implement the three class methods initialise, run, and finalise (e.g. lines 26-34 in Script 7, where the pass statements should be replaced by the actual implementation of these methods). This initialise-run-finalise (IRF) paradigm is based on the interfacing standards BMI (Peckham et al., 2013; Hutton et al., 2020) and OpenMI (Harpham et al., 2019).

Instances of newly created Component classes can then be created and, thanks to their base class, they inherit the functionality that make them readily usable in the framework, as described in section 3.

For existing models, the contributor may need to perform some refactoring of their source code, namely to comply with the framework interfaces and to comply with the initialise-run-finalise paradigm. The creation of a Python class is a requirement for use in the framework, however, the initialise, run, and finalise methods can call software which can be interfaced with Python, such as existing Fortran, C, or C++ programs.

A blank template is available on GitHub at unifhy-org/unifhycontrib-template to provide a starting point for contributors to package their new or existing models into framework compatible Python libraries. 
https://doi.org/10.5194/gmd-2021-419

Preprint. Discussion started: 16 December 2021

(c) Author(s) 2021. CC BY 4.0 License.

(c) (i)
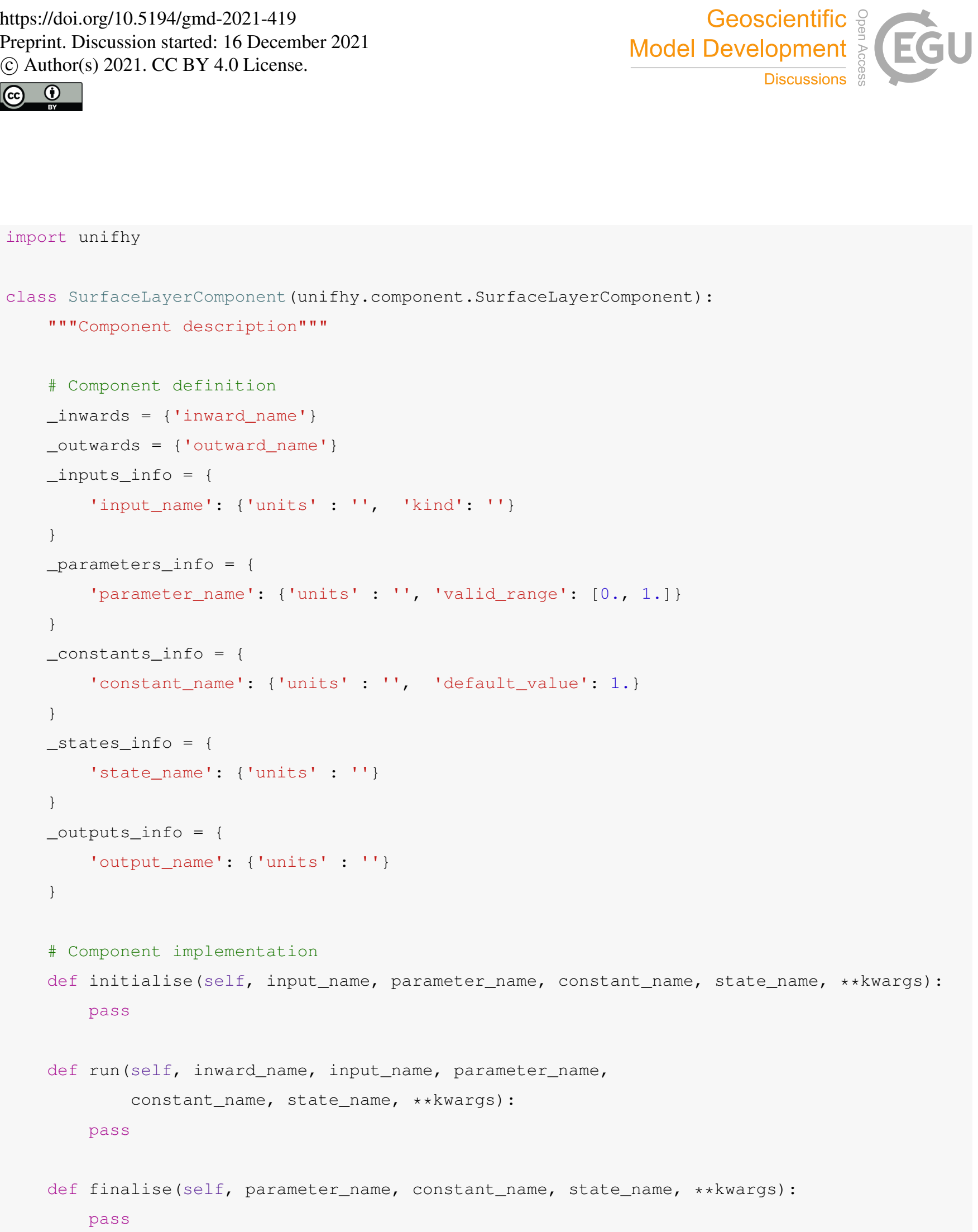

Script 7. Template for a science component contribution: example on a fictional surface layer component. 
https://doi.org/10.5194/gmd-2021-419

Preprint. Discussion started: 16 December 2021

(c) Author(s) 2021. CC BY 4.0 License.

(c) (i)

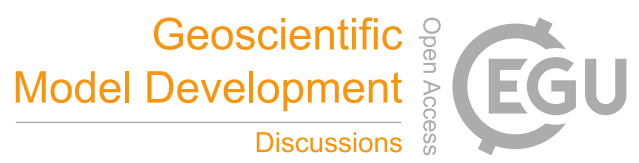

\section{Case studies using the framework}

\subsection{Selected science components}

A selection of existing models have already been refactored into science components compatible with the framework. These include the Artemis (Dadson et al., 2021), RFM (Lewis and Hallouin, 2021), and SMART (Hallouin et al., 2021) models.

The Artemis model provides a simple runoff production model designed to be comparable with the runoff-production models typically embedded within climate models, which combines Penman-Monteith evaporation (Monteith, 1965) with Rutter-Gash canopy interception (Gash, 1979), TOPMODEL runoff production (Clark and Gedney, 2008), and a degree-day-based snow accumulation and melting model (Moore et al., 1999; Hock, 2003; Beven, 2012). The River Flow Model (RFM) is a runoff routing model based on a discrete approximation of the one-directional kinematic wave with lateral inflow (Bell et al., 2007; Dadson et al., 2011). The Soil Moisture Accounting and Routing for Transport (SMART) model is a bucket-style rainfall-runoff model based on the soil layers concept (Mockler et al., 2016).

Note, the Artemis and RFM model parameters are not optimised, while the SMART model parameters are optimised for each catchment separately using a standalone version of the model (Hallouin et al., 2019) and selecting the best performing parameter set from a Latin Hypercube Sampling (McKay et al., 2000) of $10^{6}$ parameter sets, using a subset for the period 1998-2007 of the driving and observational data used by Smith et al. (2019), and the modified Kling-Gupta Efficiency (Kling et al., 2012) as objective function.

\subsection{Selected configurations}

The capabilities of the framework are demonstrated through three different configurations summarised in Table 2.

The first configuration puts the Artemis and the RFM models together to form a simple land system model. It demonstrates the flexibility in the temporal and the spatial resolutions of the various components. Indeed, the surface layer and the subsurface components are taken from the Artemis model and configured to run at an hourly timestep on a 0.5 degree resolution latitudelongitude grid, while the open water component from RFM is used and configured to run at 15-minute intervals on a 0.5/60 ( 0.008) degree resolution on a latitude-longitude grid.

The second configuration demonstrates the possibility to replace science components with datasets. To do so, the surface and subsurface runoff outputs from the JULES model (Best et al., 2011; Clark et al., 2011) available in the CHESS-land dataset (Martínez-de la Torre et al., 2018) are put together as a DataComponent and used in place of the subsurface component, which is then coupled with the open water component of the RFM model, both on a 1 kilometre resolution on the British National grid. The surface layer component is removed by setting it as a NullComponent.

The third and last configuration puts together the Artemis and SMART models. It demonstrates the possibility to substitute parts of an existing model (i.e. SMART) with parts from another model (i.e. Artemis) and explore the impacts on the model performance. The SMART model is a rainfall-runoff model for application to hydrologically meaningful spatial elements (e.g. catchments, sub-basins), for which the existing gridded space domains are irrelevant. However, the model can be run on a single 
https://doi.org/10.5194/gmd-2021-419

Preprint. Discussion started: 16 December 2021

(c) Author(s) 2021. CC BY 4.0 License.

(c) (i)

Table 2. Framework configurations.

\begin{tabular}{lllll}
\hline Framework Component & Science Component & TimeDomain & SpaceDomain & DataSet $^{1}$ \\
\hline & Configuration 1: running a simple land system model & \\
\hline SurfaceLayerComponent & Artemis & Hourly & WGS84 0.5 degree & ERA5 \\
SubSurfaceComponent & Artemis & Hourly & WGS84 0.5 degree & ERA5 \\
OpenWaterComponent & RFM & 15 minutes & WGS84 0.008 degree & HydroSHEDS \\
\hline \multirow{2}{*}{ Configuration 2: routing previously simulated runoff } & \\
\hline SurfaceLayerComponent & NullComponent & - & - & - \\
OpenWaterComponent & RFM & Daily & OSGB 1 km & CHESS-land \\
\hline \multicolumn{2}{c}{ Configuration 3: } & adding explicit surface evaporation processes in a rainfall-runoff model \\
\hline SurfaceLayerComponent & Artemis & Hourly & WGS84 0.5 degree & ERA5 \\
SubSurfaceComponent & SMART & Hourly & Catchment (one grid cell) & - \\
OpenWaterComponent & SMART & Hourly & Catchment (one grid cell) & - \\
\hline
\end{tabular}

${ }^{1}$ See Appendix A for more details on data sources.

spatial element assumed to represent the whole catchment until more complex geometries are supported in the framework (see subsection 6.2).

Note, the details of the three configurations are available as YAML configuration files in the Supplement.

\subsection{Selected study catchments}

The three configurations are applied to three British catchments, selected to explore the capabilities of the framework: the upper Severn catchment predominantly located in Wales, the Ouse catchment located in North East England, and the Tay catchment located in East Scotland (see Figure 3). These three catchments cover a range of climatological, topographical and geological settings. Their base flow indices (BFI) are 0.53, 0.39, and 0.64, respectively (Boorman et al., 1995). The three configurations applied to these three study catchments form nine case studies. The simulation period considered is 2008-2017.

\subsection{Results}

Figure 4 showcases the river discharge simulated with the three framework configurations described above, focussing on the river discharge at the catchment outlet in the line plots (a, c, e), and the spatial distribution of river discharge at the end of the simulation in the gridded plots (b, d). For reasons of brevity, only the Tay catchment is shown in the main text, figures for the other two study catchments are available in Appendix B. These figures confirm qualitatively the plausibility of the 


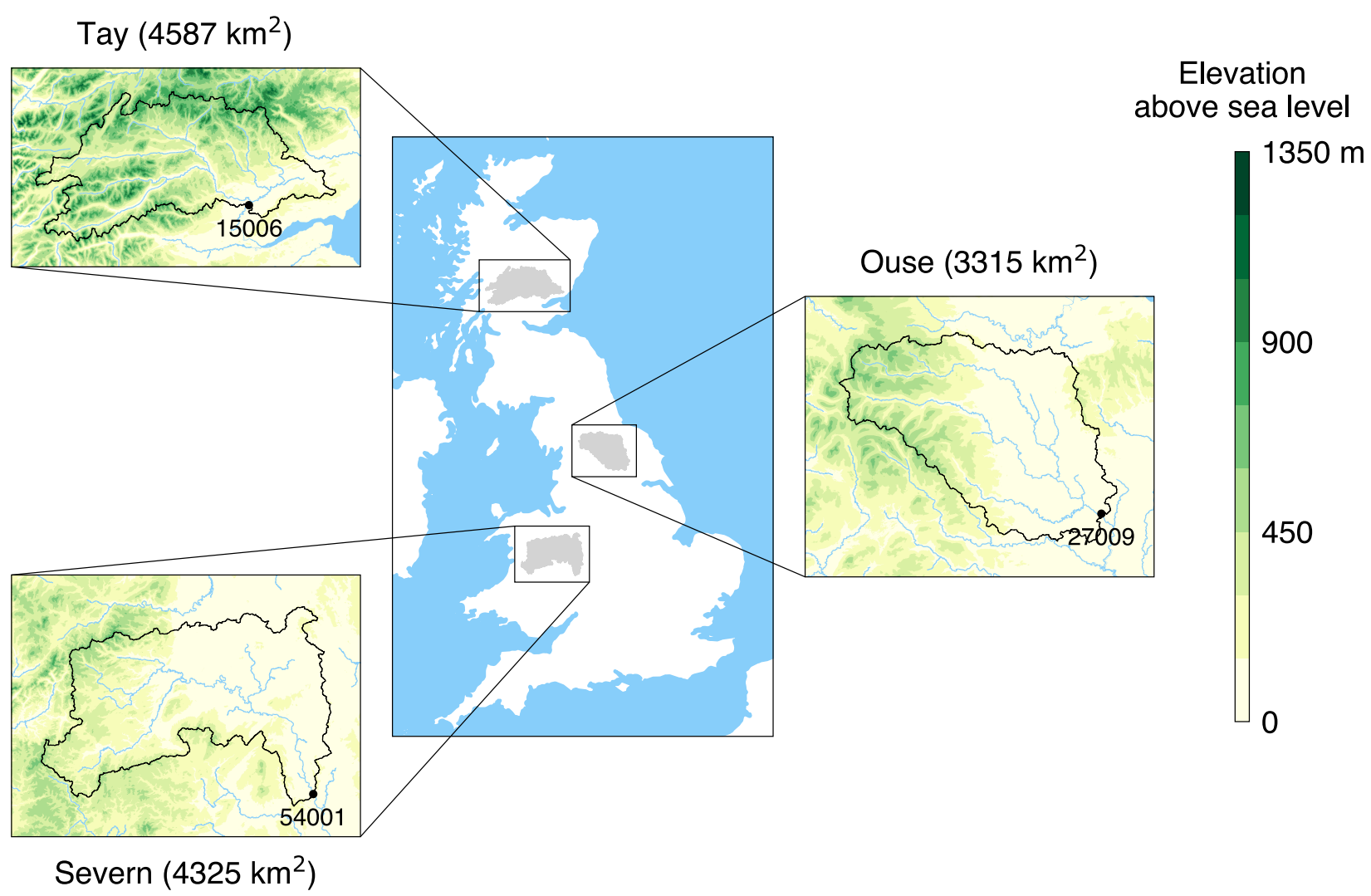

Figure 3. Location of the three study catchments in Great Britain. In the zoomed-in panels, the dots correspond to the outlets of the catchments and their adjoining five-digit labels correspond to the number of the National River Flow Archive (NRFA) hydrometric stations at these outlets. The elevation is based on digital spatial data licensed from the UK Centre for Ecology \& Hydrology, OUKCEH (Morris and Flavin, 1990, 1994).

framework simulations. Indeed, the overlaid hydrographs suggest that the overall observed discharge pattern is captured by the simulations, while the spatial distributions of river discharge sketch a realistic picture of the catchment river network.

In addition, a quantitative evaluation of the performance of the framework simulations is done with respect to the river discharge at the catchment outlet where observed and simulated time series are compared using the non-parametric Kling-Gupta efficiency $\left(R_{N P}\right)$. This is a composite metric made of three equally-weighted components $r_{S}, \alpha_{N P}$, and $\beta$, assessing the agreement in the dynamics (i.e. correlation), the variability, and the volume (i.e. bias) of the discharge time series, respectively (Pool et al., 2018). Table 3 features these metric components computed for the three configurations and the three study catchments using the Python package hydroeval (Hallouin, 2021). 
Table 3. Quantitative comparison of the three configurations for the three study catchments.

\begin{tabular}{llcccc}
\hline \multirow{2}{*}{ Catchment } & Configuration & \multicolumn{4}{c}{ Performance metrics } \\
& & $R_{\mathrm{NP}}$ & $r_{S}$ & $\alpha_{\mathrm{NP}}$ & $\beta$ \\
\hline \multirow{2}{*}{ Tay } & 1 & 0.667 & 0.692 & 0.981 & 1.126 \\
& 2 & 0.743 & 0.773 & 0.979 & 0.881 \\
& 3 & 0.766 & 0.821 & 0.940 & 1.139 \\
Ouse & 1 & 0.456 & 0.614 & 0.870 & 1.361 \\
& 2 & 0.674 & 0.705 & 0.945 & 0.875 \\
\multirow{3}{*}{ Severn } & 3 & 0.493 & 0.790 & 0.882 & 1.447 \\
& 1 & 0.495 & 0.721 & 0.909 & 1.411 \\
& 2 & 0.706 & 0.719 & 0.946 & 0.933 \\
& 3 & 0.218 & 0.840 & 0.926 & 1.762 \\
\hline
\end{tabular}

The comparative performance of the three configurations for each catchment in turn informs the most suitable combination of components for a given temporal and geographical context. For instance, the third configuration appears to be the most suitable in the Tay catchment, if one is solely interested in simulating the river discharge accurately $\left(R_{N P}\right.$ of 0.766$)$, while the second configuration would be preferred for the Ouse and Severn catchments ( $R_{N P}$ of 0.674 and 0.706, respectively). However, these conclusions are metric-dependent and the analysis of the components of the composite metric can reveal the strengths and weaknesses of a given configuration, e.g. while the third configuration performs highest on the composite metric in the Tay catchment, its ranking on capturing the flow variability is the lowest of the three configurations ( $\alpha_{N P}$ of 0.940$)$.

Some caveats in this comparison are that the third configuration used a calibrated model unlike the first and second configurations, and the second configuration used data from a model constrained to conserve mass and energy, unlike the other configurations that only conserve mass. This likely skews the comparison.

This brief analysis of the results is used to demonstrate the potential of the framework to elicit the most suitable combination of components to simulate the hydrological behaviour of a given region; it is not to draw definitive conclusions as to which combinations should be used for the catchments selected here. Moreover, this analysis focuses on one hydrological variable, the river discharge, but other hydrological variables such as e.g. soil moisture or evaporation could also be considered.

\section{Future developments}

\subsection{Implicit spatial heterogeneity}

The spatial heterogeneity of real-world hydrological processes can be accounted for in models by either adjusting the resolution of their spatial discretisation explicitly (i.e. through finer mesh elements) or implicitly (i.e. through sub-mesh units). The former is currently possible using the framework but can be computationally costly, although flexible discretisation allows 

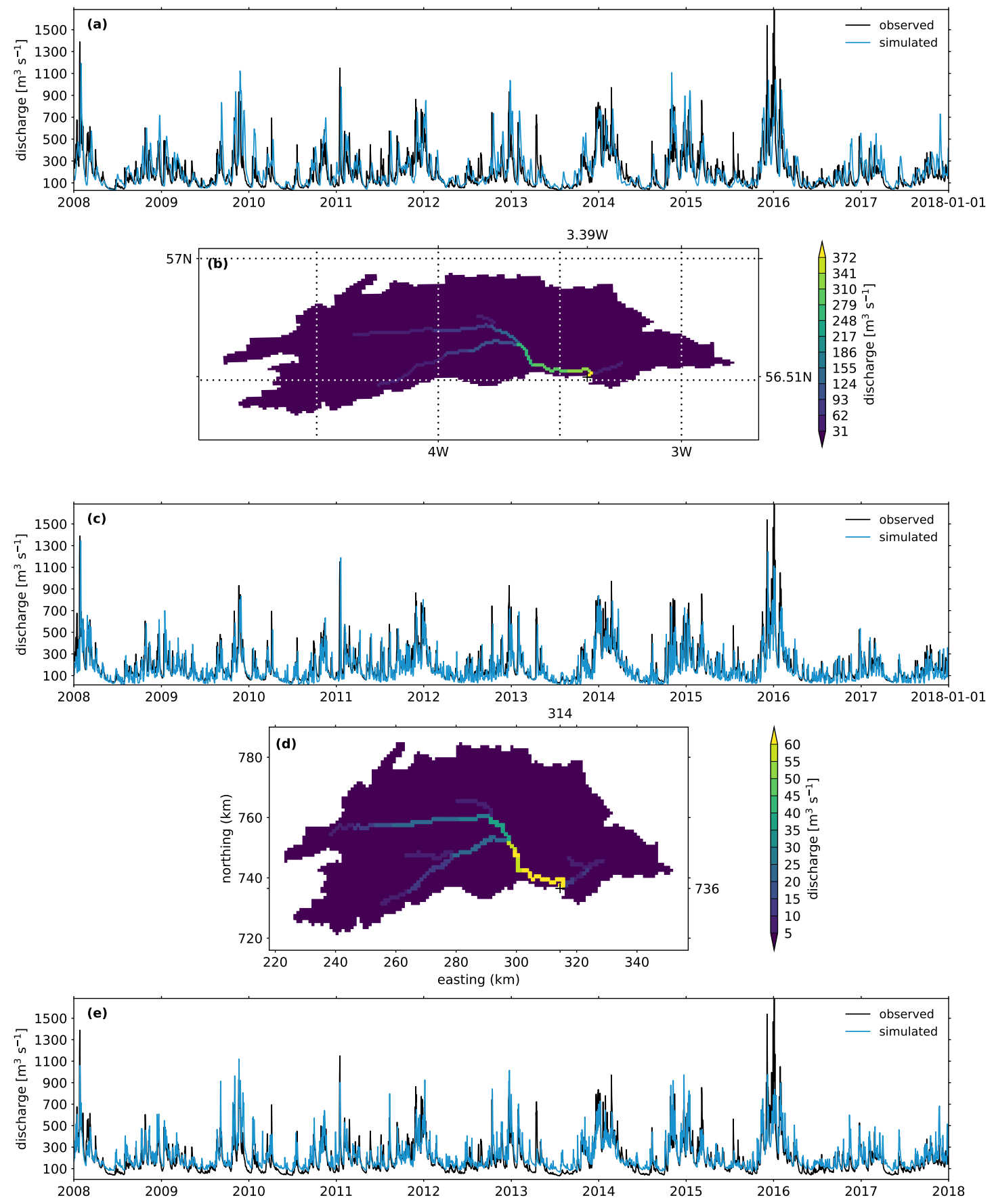

Figure 4. Simulation of the river discharge with the three configurations for the Tay catchment: (a) observed and simulated hydrographs with configuration 1 at the catchment outlet $\left[3.39^{\circ} \mathrm{W}, 56.51^{\circ} \mathrm{N}\right],(\mathbf{b})$ gridded simulated discharge with configuration 1 for the last simulation step [2018-01-01], (c) observed and simulated hydrographs with configuration 2 at the catchment outlet [314, 736], (d) gridded simulated discharge with configuration 2 for the last simulation step [2018-01-01], (e) observed and simulated hydrographs with configuration 3 at the catchment outlet. 
https://doi.org/10.5194/gmd-2021-419

Preprint. Discussion started: 16 December 2021

(c) Author(s) 2021. CC BY 4.0 License.

\section{(c) (i)}

most of the cost to be focussed on the part(s) of the water cycle where finer resolutions are justified. Implicit resolutions are not currently supported in the framework but are often used by land surface models, e.g. tiling or mosaic schemes to consider spatial heterogeneity within the grid cells of the atmospheric models to which they are coupled. These schemes consider varied biophysical behaviour depending on e.g. land cover types. Some hydrological models also use such schemes in the form of hydrological response units (HRUs), where the unit (i.e. the tile) is typically based on a combination of soil types and/or elevation bands and/or land cover types. These sub-mesh units need not be geographically located, but they can be hydrologically connected nonetheless (e.g. flow matrix in TOPMODEL (Beven and Freer, 2001) in use e.g. in HydroBlocks (Chaney et al., 2016), intra-hillslope configuration in CLM (Swenson et al., 2019), unit-to-unit routing in ORCHIDEE (Nguyen-Quang et al., 2018)). Such schemes will be valuable for later versions of the framework, although it is anticipated that such implementation will not be trivial. In addition, the explicit supermesh required in the remapping operation (see subsection 2.3) will need to be extended to consider this implicit discretisation (i.e. sub-mesh) as well.

\subsection{Unstructured spatial meshes}

Structured grids may not be sufficient for some components. For example, existing land surface layer models often inherit their spatial discretisation from an associated atmospheric model. In atmospheric models, the Earth's poles cause problems when using regular latitude-longitude discretisations because the grid cells get smaller as the coordinates converge towards the poles, therefore unstructured meshes are often preferred instead, e.g. reduced grids (e.g. ECMWF's IFS model (Hortal and Simmons, 1991)), icosahedral grids (e.g. DWD’s ICON model (Zängl et al., 2015), IPSL's DYNAMICO core (Dubos et al., 2015)), or cubed spheres (e.g. UK Met Office's LFRic model (Adams et al., 2019), NOAA's FV3 model (Putman and Lin, 2007)). Moreover, triangular grids are also used in some hydrological and hydraulic models (e.g. PIHM (Li and Duffy, 2012), CHILD model (Tucker et al., 2001)). Finally, rainfall-runoff models are typically applied on drainage basins, where space domains based on highly complex polygons may also prove useful to support such models as components for the framework.

Supporting such spatial discretisations would extend the range of models that can be refactored into components for the framework, however, current remapping functionalities may fall short to deal with these, since e.g. ESMF currently does not support unstructured grids with cells with more than four edges. In addition, unlike structured grids, unstructured grids require additional horizontal connectivity information.

\subsection{Parallel execution}

315 The framework can leverage high performance computing through internal parallelisation and through the generation of many model instances to form an ensemble of water cycle simulations.

For internal parallelisation, the modular framework is readily structured to offer opportunities for both task decomposition (i.e. execute components concurrently) and domain decomposition (i.e. compute spatial subsets of the modelled region concurrently). While we anticipate most applications using an implementation of the Message Passing Interface (MPI), there is no a priori reason why other parallelism techniques such as OpenMP or OpenACC could not be used. However, if different approaches are used in different coupled components, load balancing would likely be an issue. If task decomposition is being 
used, the relationship between components will need to consider the spatio-temporal scales being modelled in each component, e.g. coupling of "fast" physics components may require adjustments rather than increments, ruling out concurrent in favour of sequential coupling (Balaji et al., 2016). If domain decomposition is used, the distribution of the spatial supermesh on the processing elements will need to be communicated to the framework to enable the transfer of information across component, albeit the domain decomposition itself is anticipated to be the responsibility of the component contributors.

Usage in large ensemble experiments represent an "embarrassingly parallel problem" with many available implementation mechanisms. The flexibility offered by the object oriented framework design makes it easier to perturb selected aspects of a given framework configuration to produce many alternative models.

\subsection{External model coupling}

Models of the land system are typically used with atmospheric and ocean models, e.g. in Earth system models. This means that the framework will not only need to be usable standalone but also in a coupled configuration. This will involve considerations regarding memory allocation, time synchronisation, and domain decomposition. And this will require the formulation standard interfaces between the framework components and the external models (e.g. Polcher et al., 1998; Best et al., 2004). In addition, such a modular framework for the land system can contribute to the improved coarse-grained concurrency of Earth system models (Balaji et al., 2016; Lawrence et al., 2018).

\section{Conclusions}

This framework represents the first implementation of a new modular blueprint to model the terrestrial water cycle. It is open source and comes with extended online documentation. By design, this Python package is intended to be easy to use, with a low entry bar for people with little programming experience. Indeed, installing a Python package is straightforward and only a few steps in a Python script are needed to set up and run a complete model in a Jupyter notebook, which is likely to prove useful for teaching and training activities alike. It is also intended to be easily customisable, through choosing from a library of compatible components those most suitable for a given region and for a given objective. Finally, it is intended to be easily extensible by creating new components, which should streamline the development and sharing of new science for the terrestrial water cycle.

Later versions of the framework will implement the additional developments discussed in section 6. In addition, the extension of the blueprint to include other geochemical cycles (e.g. carbon, nitrogen, phosphorus) as well as anthropogenic influences is planned. In the meantime, we hope that the science library will grow with new contributions from the land, hydrology, and groundwater modelling communities, and stimulate collaborations between them. 
https://doi.org/10.5194/gmd-2021-419

Preprint. Discussion started: 16 December 2021

(c) Author(s) 2021. CC BY 4.0 License.

(c) (i)

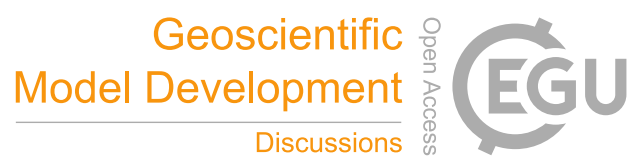

350 Code availability. The framework is open source and available on GitHub in the repository unifhy-org/unifhy. The science components Artemis, RFM, and SMART are also open source and available on GitHub in the repositories unifhy-org/unifhycontrib-artemis, unifhyorg/unifhycontrib-rfm, and unifhy-org/unifhycontrib-smart, respectively. The online documentation is accessible at unifhy-org.github.io/unifhy

Data availability. The input data used in the case studies is publicly available using the references provided in Appendix A. The observed river flow data is publicly available from NRFA (http://nrfa.ceh.ac.uk/, last access: 10 October 2021). The framework output data is available upon request from the corresponding author.

\section{Appendix A: Data sources}

Table A1. Sources for data used in configuration 1.

\begin{tabular}{llll}
\hline Variable name & Dataset name & Data DOI & Related publications \\
\hline $\begin{array}{l}\text { precipitation flux } \\
\text { specific humidity }\end{array}$ & ERA5 & $10.24381 /$ cds.20d54e34 & Cucchi et al. (2020) \\
$\begin{array}{l}\text { surface downwelling shortwave flux in air } \\
\text { surface downwelling longwave flux in air }\end{array}$ & & & \\
$\begin{array}{l}\text { air temperature } \\
\text { wind speed }\end{array}$ & - & & \\
surface albedo ${ }^{1}$ & GLAS & - & - \\
vegetation height & MOD15A2H & $10.5067 /$ MODIS/ & Los et al. (2012) \\
leaf area index & & MOD15A2H.006 & \\
& HWSD & - & Nachtergaele et al. (2012) \\
\hline topmodel saturation capacity & & - & Marthews et al. (2015) \\
saturated hydraulic conductivity & - & - & Lehner et al. (2008); \\
topographic index & HydroSHEDS & & Lehner and Grill (2013) \\
\hline $\begin{array}{l}\text { flow direction } \\
\text { flow accumulation }\end{array}$ & & &
\end{tabular}

\footnotetext{
${ }^{1}$ Produced using suite u-ag343 accessible at https://code.metoffice.gov.uk/trac/roses-u.
} 
https://doi.org/10.5194/gmd-2021-419

Preprint. Discussion started: 16 December 2021

(c) Author(s) 2021. CC BY 4.0 License.

(c) (i)

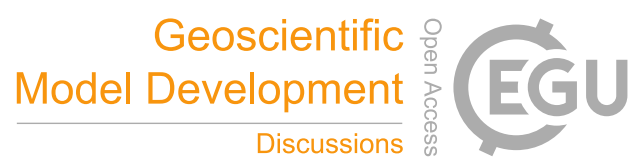

Table A2. Sources for data used in configuration 2.

\begin{tabular}{llll}
\hline Variable name & Dataset name & Data DOI & Related publications \\
\hline surface_runoff_flux & CHESS-land & $\begin{array}{l}10.5285 / c 76096 \mathrm{~d} 6- \\
45 \mathrm{~d} 4-4 \mathrm{a} 69-\mathrm{a} 310-\end{array}$ & $\begin{array}{l}\text { Martínez-de la Torre } \\
\text { et al. (2018) }\end{array}$ \\
subsurface_runoff_flux & & $4 \mathrm{c} 67 \mathrm{f} 8 \mathrm{dcf096}$ & \\
& & - & Davies and Bell (2009); \\
flow_direction & - & & Martínez-de la Torre \\
flow_accumulation & & & et al. (2019) \\
\hline
\end{tabular}

Table A3. Sources for data used in configuration 3.

\begin{tabular}{llll}
\hline Variable name & Dataset name & Data DOI & Related publications \\
\hline $\begin{array}{l}\text { precipitation flux } \\
\text { specific humidity }\end{array}$ & ERA5 & $10.24381 /$ cds.20d54e34 & Cucchi et al. (2020) \\
$\begin{array}{l}\text { surface downwelling shortwave flux in air } \\
\text { surface downwelling longwave flux in air }\end{array}$ & & & \\
air temperature & & & \\
wind speed & - & & \\
surface albedo ${ }^{1}$ & GLAS & - & - \\
vegetation height & MOD15A2H & $10.5067 / M O D I S /$ & - \\
leaf area index & & MOD15A2H.006 & \\
& & & \\
\hline
\end{tabular}

${ }^{1}$ Produced using suite u-ag343 accessible at https://code.metoffice.gov.uk/trac/roses-u.

\section{Appendix B: Additional results}

Author contributions. All co-authors designed the blueprint for the framework. TH and RJE developed the framework implementation in Python. TH performed the simulations. TH and RJE processed the simulation outputs. TH prepared the manuscript with contributions from all co-authors. 

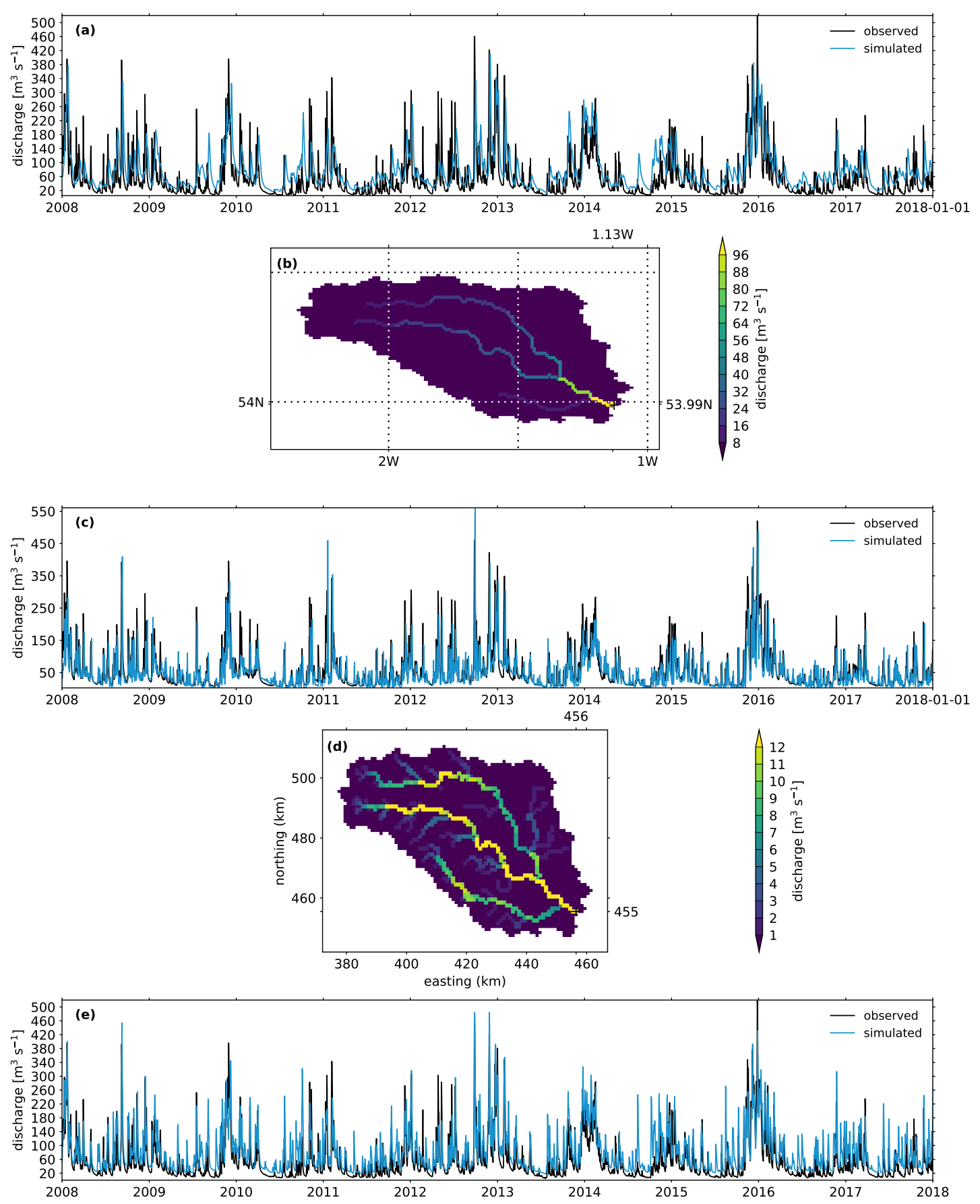

Figure B1. Simulation of the river discharge with the three configurations for the Ouse catchment: (a) observed and simulated hydrographs with configuration 1 at the catchment outlet $\left[1.13^{\circ} \mathrm{W}, 53.99^{\circ} \mathrm{N}\right],(\mathbf{b})$ gridded simulated discharge with configuration 1 for the last simulation step [2018-01-01], (c) observed and simulated hydrographs with configuration 2 at the catchment outlet [456, 455], (d) gridded simulated discharge with configuration 2 for the last simulation step [2018-01-01], (e) observed and simulated hydrographs with configuration 3 at the catchment outlet. 

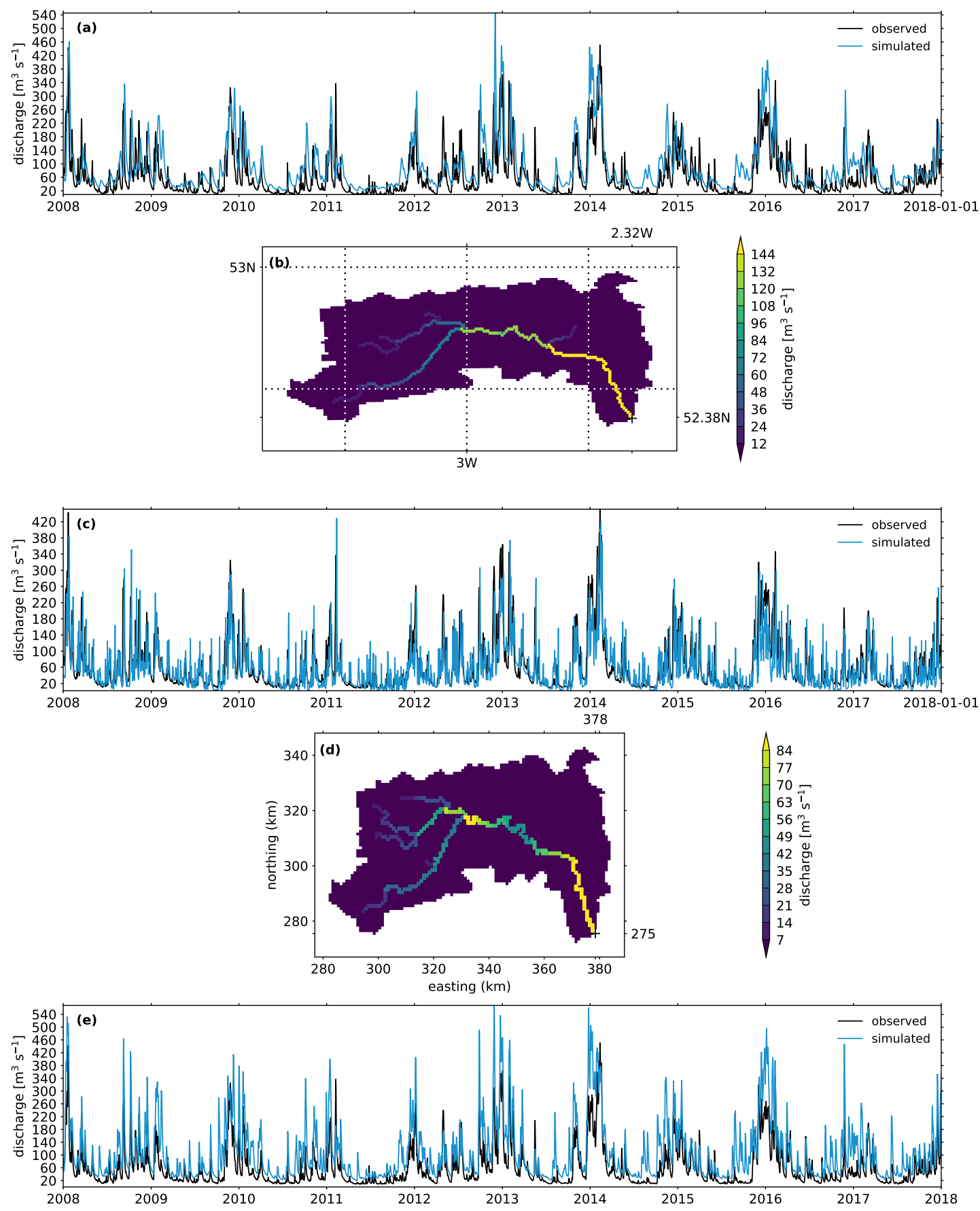

Figure B2. Simulation of the river discharge with the three configurations for the Severn catchment: (a) observed and simulated hydrographs with configuration 1 at the catchment outlet $\left[2.32^{\circ} \mathrm{W}, 52.38^{\circ} \mathrm{N}\right]$, (b) gridded simulated discharge with configuration 1 for the last simulation step [2018-01-01], (c) observed and simulated hydrographs with configuration 2 at the catchment outlet [378, 275], (d) gridded simulated discharge with configuration 2 for the last simulation step [2018-01-01], (e) observed and simulated hydrographs with configuration 3 at the catchment outlet. 
https://doi.org/10.5194/gmd-2021-419

Preprint. Discussion started: 16 December 2021

(C) Author(s) 2021. CC BY 4.0 License.

(c) (i)

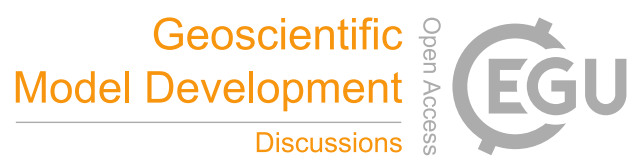

Competing interests. The authors declare that they have no conflict of interests.

Acknowledgements. This work was funded by the Natural Environment Research Council (NERC) as part of the Hydro-JULES programme (NE/S017380/1). The authors would like to thank the developers of $\mathrm{cf-python,} \mathrm{David} \mathrm{Hassell} \mathrm{and} \mathrm{Sadie} \mathrm{Bartholomew,} \mathrm{for} \mathrm{implementing}$ the requested features required by the framework, and Andy Heaps for the cf-plot support. They would also like to thank Katie Facer-

365 Childs for providing the rainfall and potential evapotranspiration data used to calibrate the SMART model, Helen Davies for providing the HydroSHEDS dataset, and Huw Lewis for providing a Python version of RFM used to create an open water component for use in the framework. 
https://doi.org/10.5194/gmd-2021-419

Preprint. Discussion started: 16 December 2021

(c) Author(s) 2021. CC BY 4.0 License.

(c) (i)

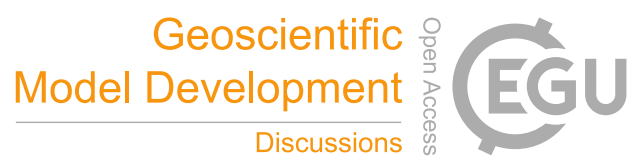

\section{References}

Adams, S., Ford, R., Hambley, M., Hobson, J., Kavčič, I., Maynard, C., Melvin, T., Müller, E., Mullerworth, S., Porter, A., Rezny, M.,

Shipway, B., and Wong, R.: LFRic: Meeting the challenges of scalability and performance portability in Weather and Climate models, Journal of Parallel and Distributed Computing, 132, 383-396, https://doi.org/https://doi.org/10.1016/j.jpdc.2019.02.007, 2019.

Balaji, V., Benson, R., Wyman, B., and Held, I.: Coarse-grained component concurrency in Earth system modeling: parallelizing atmospheric radiative transfer in the GFDL AM3 model using the Flexible Modeling System coupling framework, Geoscientific Model Development, 9, 3605-3616, https://doi.org/10.5194/gmd-9-3605-2016, 2016.

Bell, V. A., Kay, A. L., Jones, R. G., and Moore, R. J.: Development of a high resolution grid-based river flow model for use with regional climate model output, Hydrology and Earth System Sciences, 11, 532-549, https://doi.org/10.5194/hess-11-532-2007, 2007.

Best, M. J., Beljaars, A., Polcher, J., and Viterbo, P.: A Proposed Structure for Coupling Tiled Surfaces with the Planetary Boundary Layer, Journal of Hydrometeorology, 5, 1271 - 1278, https://doi.org/10.1175/JHM-382.1, 2004.

Best, M. J., Pryor, M., Clark, D. B., Rooney, G. G., Essery, R. L. H., Ménard, C. B., Edwards, J. M., Hendry, M. A., Porson, A., Gedney, N., Mercado, L. M., Sitch, S., Blyth, E., Boucher, O., Cox, P. M., Grimmond, C. S. B., and Harding, R. J.: The Joint UK Land Environment Simulator (JULES), model description - Part 1: Energy and water fluxes, Geoscientific Model Development, 4, 677-699, https://doi.org/10.5194/gmd-4-677-2011, 2011.

Beven, K.: Rainfall-Runoff Modelling: The Primer, vol. 3204, Wiley-Blackwell, 2nd ed. edn., https://doi.org/10.1002/9781119951001, 2012.

Beven, K. and Freer, J.: A dynamic TOPMODEL, Hydrological Processes, 15, 1993-2011, https://doi.org/10.1002/hyp.252, 2001.

Boorman, D. B., Hollis, J. M., and Lilly, A.: Hydrology of soil types: a hydrologically-based classification of the soils of United Kingdom, Institute of Hydrology, Wallingford, 1995.

Chaney, N. W., Metcalfe, P., and Wood, E. F.: HydroBlocks: a field-scale resolving land surface model for application over continental extents, Hydrological Processes, 30, 3543-3559, https://doi.org/10.1002/hyp.10891, 2016.

Clark, D. B. and Gedney, N.: Representing the effects of subgrid variability of soil moisture on runoff generation in a land surface model, Journal of Geophysical Research: Atmospheres, 113, https://doi.org/10.1029/2007JD008940, 2008.

Clark, D. B., Mercado, L. M., Sitch, S., Jones, C. D., Gedney, N., Best, M. J., Pryor, M., Rooney, G. G., Essery, R. L. H., Blyth, E., Boucher, O., Harding, R. J., Huntingford, C., and Cox, P. M.: The Joint UK Land Environment Simulator (JULES), model description - Part 2: Carbon fluxes and vegetation dynamics, Geoscientific Model Development, 4, 701-722, https://doi.org/10.5194/gmd-4-701-2011, 2011.

Clark, M. P., Slater, A. G., Rupp, D. E., Woods, R. A., Vrugt, J. A., Gupta, H. V., Wagener, T., and Hay, L. E.: Framework for Understanding Structural Errors (FUSE): A modular framework to diagnose differences between hydrological models, Water Resources Research, 44, https://doi.org/10.1029/2007WR006735, 2008.

Clark, M. P., Nijssen, B., Lundquist, J. D., Kavetski, D., Rupp, D. E., Woods, R. A., Freer, J. E., Gutmann, E. D., Wood, A. W., Brekke, L. D., Arnold, J. R., Gochis, D. J., and Rasmussen, R. M.: A unified approach for process-based hydrologic modeling: 1. Modeling concept, Water Resources Research, 51, 2498-2514, https://doi.org/10.1002/2015WR017198, 2015. tation of Components in the Earth System Modeling Framework, The International Journal of High Performance Computing Applications, 19, 341-350, https://doi.org/10.1177/1094342005056120, 2005.

Craig, A., Valcke, S., and Coquart, L.: Development and performance of a new version of the OASIS coupler, OASIS3-MCT_3.0, Geoscientific Model Development, 10, 3297-3308, https://doi.org/10.5194/gmd-10-3297-2017, 2017. 
https://doi.org/10.5194/gmd-2021-419

Preprint. Discussion started: 16 December 2021

(c) Author(s) 2021. CC BY 4.0 License.

(c) (i)

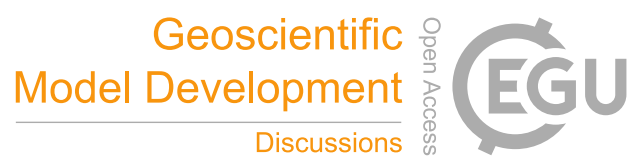

Craig, A. P., Vertenstein, M., and Jacob, R.: A new flexible coupler for earth system modeling developed for CCSM4 and CESM1, The International Journal of High Performance Computing Applications, 26, 31-42, https://doi.org/10.1177/1094342011428141, 2012.

Craig, J. R., Brown, G., Chlumsky, R., Jenkinson, R. W., Jost, G., Lee, K., Mai, J., Serrer, M., Sgro, N., Shafii, M., Snowdon, A. P., and Tolson, B. A.: Flexible watershed simulation with the Raven hydrological modelling framework, Environmental Modelling \& Software, 129, 104 728, https://doi.org/10.1016/j.envsoft.2020.104728, 2020.

410 Cucchi, M., Weedon, G. P., Amici, A., Bellouin, N., Lange, S., Müller Schmied, H., Hersbach, H., and Buontempo, C.: WFDE5: bias-adjusted ERA5 reanalysis data for impact studies, Earth System Science Data, 12, 2097-2120, https://doi.org/10.5194/essd-12-2097-2020, 2020.

Dadson, S., Bell, V., and Jones, R.: Evaluation of a grid-based river flow model configured for use in a regional climate model, Journal of Hydrology, 411, 238-250, https://doi.org/10.1016/j.jhydrol.2011.10.002, 2011.

Dadson, S. J., Hallouin, T., and Ellis, R.: unifhycontrib-artemis, https://doi.org/10.5281/zenodo.5779947, 2021.

Davies, H. N. and Bell, V. A.: Assessment of methods for extracting low-resolution river networks from high-resolution digital data, Hydrological Sciences Journal, 54, 17-28, https://doi.org/10.1623/hysj.54.1.17, 2009.

Dubos, T., Dubey, S., Tort, M., Mittal, R., Meurdesoif, Y., and Hourdin, F.: DYNAMICO-1.0, an icosahedral hydrostatic dynamical core designed for consistency and versatility, Geoscientific Model Development, 8, 3131-3150, https://doi.org/10.5194/gmd-8-3131-2015, 2015.

Eaton, B., Gregory, J., Drach, B., Taylor, K., Hankin, S., Blower, J., Caron, J., Signell, R., Bentley, P., Rappa, G., Höck, H., Pamment, A., Juckes, M., Raspaud, M., Horne, R., Whiteaker, T., Blodgett, D., Zender, C., and Lee, D.: NetCDF Climate and Forecast (CF) Metadata Conventions, http://cfconventions.org/Data/cf-conventions/cf-conventions-1.8/cf-conventions.html, 2020.

Eyring, V., Bony, S., Meehl, G. A., Senior, C. A., Stevens, B., Stouffer, R. J., and Taylor, K. E.: Overview of the Coupled Model Intercomparison Project Phase 6 (CMIP6) experimental design and organization, Geoscientific Model Development, 9, 1937-1958, https://doi.org/10.5194/gmd-9-1937-2016, 2016.

Farrell, P., Piggott, M., Pain, C., Gorman, G., and Wilson, C.: Conservative interpolation between unstructured meshes via supermesh construction, Computer Methods in Applied Mechanics and Engineering, 198, 2632-2642, https://doi.org/10.1016/j.cma.2009.03.004, 2009.

Fenicia, F., Kavetski, D., and Savenije, H. H. G.: Elements of a flexible approach for conceptual hydrological modeling: 1. Motivation and theoretical development, Water Resources Research, 47, https://doi.org/10.1029/2010WR010174, 2011.

Gash, J. H. C.: An analytical model of rainfall interception by forests, Quarterly Journal of the Royal Meteorological Society, 105, 43-55, https://doi.org/10.1002/qj.49710544304, 1979.

Hallouin, T.: hydroeval: an evaluator for streamflow time series in Python, https://doi.org/10.5281/zenodo.4709652, 2021.

Hallouin, T. and Ellis, R. J.: unifhy, https://doi.org/10.5281/zenodo.5764773, Funded by the Natural Environment Research Council (NERC) Hydro-JULES programme (NE/S017380/1)., 2021.

435 Hallouin, T., Mockler, E., and Bruen, M.: SMARTpy: Conceptual Rainfall-Runoff Model, https://doi.org/10.5281/zenodo.3376589, 2019.

Hallouin, T., Mockler, E. M., and Bruen, M.: unifhycontrib-smart, https://doi.org/10.5281/zenodo.5780113, 2021.

Hanke, M., Redler, R., Holfeld, T., and Yastremsky, M.: YAC 1.2.0: new aspects for coupling software in Earth system modelling, Geoscientific Model Development, 9, 2755-2769, https://doi.org/10.5194/gmd-9-2755-2016, 2016.

Harpham, Q., Hughes, A., and Moore, R.: Introductory overview: The OpenMI 2.0 standard for integrating numerical models, Environmental Modelling \& Software, 122, 104 549, https://doi.org/10.1016/j.envsoft.2019.104549, 2019.

Hassell, D. and Bartholomew, S. L.: cfdm: A Python reference implementation of the CF data model, Journal of Open Source Software, 5, 2717, https://doi.org/10.21105/joss.02717, 2020. 
https://doi.org/10.5194/gmd-2021-419

Preprint. Discussion started: 16 December 2021

(c) Author(s) 2021. CC BY 4.0 License.

(c) (i)

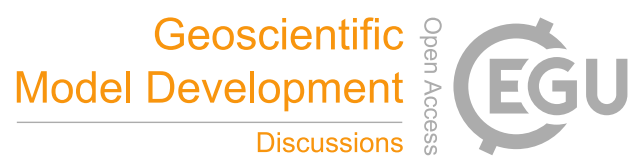

Hassell, D., Gregory, J., Blower, J., Lawrence, B. N., and Taylor, K. E.: A data model of the Climate and Forecast metadata conventions (CF1.6) with a software implementation (cf-python v2.1), Geoscientific Model Development, 10, 4619-4646, https://doi.org/10.5194/gmd10-4619-2017, 2017.

Hobley, D. E. J., Adams, J. M., Nudurupati, S. S., Hutton, E. W. H., Gasparini, N. M., Istanbulluoglu, E., and Tucker, G. E.: Creative computing with Landlab: an open-source toolkit for building, coupling, and exploring two-dimensional numerical models of Earth-surface dynamics, Earth Surface Dynamics, 5, 21-46, https://doi.org/10.5194/esurf-5-21-2017, 2017.

Hock, R.: Temperature index melt modelling in mountain areas, Journal of Hydrology, 282, 104-115, https://doi.org/10.1016/S00221694(03)00257-9, mountain Hydrology and Water Resources, 2003.

Hortal, M. and Simmons, A. J.: Use of Reduced Gaussian Grids in Spectral Models, Monthly Weather Review, 119, 1057-1074, https://doi.org/10.1175/1520-0493(1991)119<1057:UORGGI>2.0.CO;2, 1991

Hutton, E., Piper, M., Drost, N., Gan, T., Kettner, A., Overeem, I., Stewart, S., and Wang, K.: The Python Modeling Toolkit (PyMT), https://doi.org/10.5281/zenodo.4985222, 2021.

Hutton, E. W., Piper, M. D., and Tucker, G. E.: The Basic Model Interface 2.0: A standard interface for coupling numerical models in the geosciences, Journal of Open Source Software, 5, 2317, https://doi.org/10.21105/joss.02317, 2020.

Kling, H., Fuchs, M., and Paulin, M.: Runoff conditions in the upper Danube basin under an ensemble of climate change scenarios, Journal of Hydrology, 424-425, 264-277, https://doi.org/10.1016/j.jhydrol.2012.01.011, 2012.

Kraft, P., Vaché, K. B., Frede, H.-G., and Breuer, L.: CMF: A Hydrological Programming Language Extension For Integrated Catchment Models, Environmental Modelling \& Software, 26, 828-830, https://doi.org/10.1016/j.envsoft.2010.12.009, 2011.

Krinner, G., Viovy, N., de Noblet-Ducoudré, N., Ogée, J., Polcher, J., Friedlingstein, P., Ciais, P., Sitch, S., and Prentice, I. C.: A dynamic global vegetation model for studies of the coupled atmosphere-biosphere system, Global Biogeochemical Cycles, 19, https://doi.org/10.1029/2003GB002199, 2005.

Lawrence, B. N., Rezny, M., Budich, R., Bauer, P., Behrens, J., Carter, M., Deconinck, W., Ford, R., Maynard, C., Mullerworth, S., Osuna, C., Porter, A., Serradell, K., Valcke, S., Wedi, N., and Wilson, S.: Crossing the chasm: how to develop weather and climate models for next generation computers?, Geoscientific Model Development, 11, 1799-1821, https://doi.org/10.5194/gmd-11-1799-2018, 2018.

Lawrence, D. M., Fisher, R. A., Koven, C. D., Oleson, K. W., Swenson, S. C., Bonan, G., Collier, N., Ghimire, B., van Kampenhout, L., Kennedy, D., Kluzek, E., Lawrence, P. J., Li, F., Li, H., Lombardozzi, D., Riley, W. J., Sacks, W. J., Shi, M., Vertenstein, M., Wieder, W. R., Xu, C., Ali, A. A., Badger, A. M., Bisht, G., van den Broeke, M., Brunke, M. A., Burns, S. P., Buzan, J., Clark, M., Craig, A., Dahlin, K., Drewniak, B., Fisher, J. B., Flanner, M., Fox, A. M., Gentine, P., Hoffman, F., Keppel-Aleks, G., Knox, R., Kumar, S., Lenaerts, J., Leung, L. R., Lipscomb, W. H., Lu, Y., Pandey, A., Pelletier, J. D., Perket, J., Randerson, J. T., Ricciuto, D. M., Sanderson, B. M., Slater, A., Subin, Z. M., Tang, J., Thomas, R. Q., Val Martin, M., and Zeng, X.: The Community Land Model Version 5: Description of New Features, Benchmarking, and Impact of Forcing Uncertainty, Journal of Advances in Modeling Earth Systems, 11, 4245-4287, https://doi.org/10.1029/2018MS001583, 2019.

Lehner, B. and Grill, G.: Global river hydrography and network routing: baseline data and new approaches to study the world's large river systems, Hydrological Processes, 27, 2171-2186, https://doi.org/10.1002/hyp.9740, 2013.

Lehner, B., Verdin, K., and Jarvis, A.: New Global Hydrography Derived From Spaceborne Elevation Data, Eos, Transactions American Geophysical Union, 89, 93-94, https://doi.org/10.1029/2008EO100001, 2008.

Lewis, H. and Hallouin, T.: unifhycontrib-rfm, https://doi.org/10.5281/zenodo.5780054, 2021. 
https://doi.org/10.5194/gmd-2021-419

Preprint. Discussion started: 16 December 2021

(c) Author(s) 2021. CC BY 4.0 License.

(c) (i)

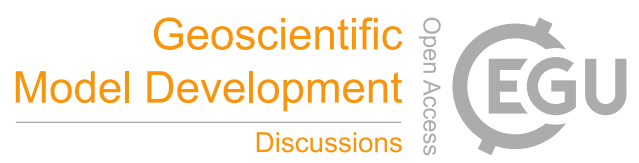

Li, S. and Duffy, C. J.: Fully-Coupled Modeling of Shallow Water Flow and Pollutant Transport on Unstructured Grids, Procedia Environmental Sciences, 13, 2098-2121, https://doi.org/10.1016/j.proenv.2012.01.200, 18th Biennial ISEM Conference on Ecological Modelling for Global Change and Coupled Human and Natural System, 2012.

Los, S. O., Rosette, J. A. B., Kljun, N., North, P. R. J., Chasmer, L., Suárez, J. C., Hopkinson, C., Hill, R. A., van Gorsel, E., Mahoney, C., and Berni, J. A. J.: Vegetation height and cover fraction between $60^{\circ} \mathrm{S}$ and $60^{\circ} \mathrm{N}$ from ICESat GLAS data, Geoscientific Model Development, 5, 413-432, https://doi.org/10.5194/gmd-5-413-2012, 2012.

Marthews, T. R., Dadson, S. J., Lehner, B., Abele, S., and Gedney, N.: High-resolution global topographic index values for use in large-scale hydrological modelling, Hydrology and Earth System Sciences, 19, 91-104, https://doi.org/10.5194/hess-19-91-2015, 2015.

Martínez-de la Torre, A., Blyth, E., and Robinson, E.: Water, carbon and energy fluxes simulation for Great Britain using the JULES Land Surface Model and the Climate Hydrology and Ecology research Support System meteorology dataset (1961-2015) [CHESS-land], https://doi.org/10.5285/c76096d6-45d4-4a69-a310-4c67f8dcf096, 2018.

Martínez-de la Torre, A., Blyth, E. M., and Weedon, G. P.: Using observed river flow data to improve the hydrological functioning of the JULES land surface model (vn4.3) used for regional coupled modelling in Great Britain (UKC2), Geoscientific Model Development, 12 , 765-784, https://doi.org/10.5194/gmd-12-765-2019, 2019.

McKay, M. D., Beckman, R. J., and Conover, W. J.: A Comparison of Three Methods for Selecting Values of Input Variables in the Analysis of Output From a Computer Code, Technometrics, 42, 55-61, https://doi.org/10.1080/00401706.2000.10485979, 2000.

Mockler, E. M., O’Loughlin, F. E., and Bruen, M.: Understanding hydrological flow paths in conceptual catchment models using uncertainty and sensitivity analysis, Computers \& Geosciences, 90, 66-77, https://doi.org/10.1016/j.cageo.2015.08.015, uncertainty and Sensitivity in Surface Dynamics Modeling, 2016.

Monteith, J. L.: Evaporation and environment, Symposia of the Society for Experimental Biology, 19, 205-234, https://repository.rothamsted. ac.uk/item/8v5v7, 1965.

Moore, R. J., Bell, V. A., Austin, R. M., and Harding, R. J.: Methods for snowmelt forecasting in upland Britain, Hydrology and Earth System Sciences, 3, 233-246, https://doi.org/10.5194/hess-3-233-1999, 1999.

Morris, D. G. and Flavin, R. W.: A digital terrain model for hydrology, in: Proc. 4th International Symposium on Spatial Data Handling, edited by Brassel, K. and H., K., vol. 1, pp. 250-262, Zurich, 1990.

Morris, D. G. and Flavin, R. W.: Sub-set of UK 50 m by 50 m hydrological digital terrain model grids, NERC, Institute of Hydrology, Wallingford, 1994.

Nachtergaele, F., van Velthuizen, H., Verelst, L., Wiberg, D., Batjes, N., Dijkshoorn, J., van Engelen, V., Fischer, G., Jones, A., Montanarella, L., Petri, M., Prieler, S., Teixeira, E., and Shi, X.: Harmonized World Soil Database (version 1.2), Food and Agriculture Organization of the UN, International Institute for Applied Systems Analysis, ISRIC - World Soil Information, Institute of Soil Science - Chinese Academy of Sciences, Joint Research Centre of the EC, 2012.

Nguyen-Quang, T., Polcher, J., Ducharne, A., Arsouze, T., Zhou, X., Schneider, A., and Fita, L.: ORCHIDEE-ROUTING: revising the river routing scheme using a high-resolution hydrological database, Geoscientific Model Development, 11, 4965-4985, https://doi.org/10.5194/gmd-11-4965-2018, 2018.

Peckham, S. D., Hutton, E. W., and Norris, B.: A component-based approach to integrated modeling in the geosciences: The design of

CSDMS, Computers \& Geosciences, 53, 3-12, https://doi.org/10.1016/j.cageo.2012.04.002, modeling for Environmental Change, 2013. 
https://doi.org/10.5194/gmd-2021-419

Preprint. Discussion started: 16 December 2021

(c) Author(s) 2021. CC BY 4.0 License.

(c) (1)

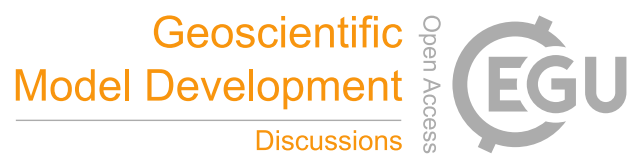

Polcher, J., McAvaney, B., Viterbo, P., Gaertner, M.-A., Hahmann, A., Mahfouf, J.-F., Noilhan, J., Phillips, T., Pitman, A., Schlosser, C., Schulz, J.-P., Timbal, B., Verseghy, D., and Xue, Y.: A proposal for a general interface between land surface schemes and general circulation models, Global and Planetary Change, 19, 261-276, https://doi.org/10.1016/S0921-8181(98)00052-6, 1998.

Pool, S., Vis, M., and Seibert, J.: Evaluating model performance: towards a non-parametric variant of the Kling-Gupta efficiency, Hydrological Sciences Journal, 63, 1941-1953, https://doi.org/10.1080/02626667.2018.1552002, 2018.

Putman, W. M. and Lin, S.-J.: Finite-volume transport on various cubed-sphere grids, Journal of Computational Physics, 227, 55-78, https://doi.org/https://doi.org/10.1016/j.jcp.2007.07.022, 2007.

Smith, K. A., Barker, L. J., Tanguy, M., Parry, S., Harrigan, S., Legg, T. P., Prudhomme, C., and Hannaford, J.: A multi-objective ensemble approach to hydrological modelling in the UK: an application to historic drought reconstruction, Hydrology and Earth System Sciences, 23, 3247-3268, https://doi.org/10.5194/hess-23-3247-2019, 2019.

Swenson, S. C., Clark, M., Fan, Y., Lawrence, D. M., and Perket, J.: Representing Intrahillslope Lateral Subsurface Flow in the Community Land Model, Journal of Advances in Modeling Earth Systems, 11, 4044-4065, https://doi.org/10.1029/2019MS001833, 2019.

Tucker, G. E., Lancaster, S. T., Gasparini, N. M., Bras, R. L., and Rybarczyk, S. M.: An object-oriented framework for distributed hydrologic and geomorphic modeling using triangulated irregular networks, Computers \& Geosciences, 27, 959-973, https://doi.org/10.1016/S00983004(00)00134-5, 2001.

Valcke, S.: The OASIS3 coupler: a European climate modelling community software, Geoscientific Model Development, 6, 373-388, https://doi.org/10.5194/gmd-6-373-2013, 2013.

Zängl, G., Reinert, D., Rípodas, P., and Baldauf, M.: The ICON (ICOsahedral Non-hydrostatic) modelling framework of DWD and MPI-M: Description of the non-hydrostatic dynamical core, Quarterly Journal of the Royal Meteorological Society, 141, 563-579, https://doi.org/10.1002/qj.2378, 2015. 